\title{
Intoxicação em ovinos por Nierembergia veitchii: observações em quatro surtos
}

\author{
Poisoning in sheep by Nierembergia veitchii: observations in four outbreaks
}

\author{
Daniel Ricardo Rissi ${ }^{I}$ Raquel Rubia Rech ${ }^{\mathrm{I}}$ Felipe Pierezan ${ }^{\mathrm{I}}$ \\ Glaucia Denise Kommers ${ }^{\text {II }}$ Claudio Severo Lombardo de Barros*II
}

\section{RESUMO}

Foram observados casos de morte súbita e doença crônica e caquetizante em ovinos provenientes de quatro rebanhos localizados em três municípios do Rio Grande do Sul, Brasil, entre junho de 2001 e maio de 2006. De uma população total sob risco de 460 ovinos, 43 foram afetados, 29 morreram espontaneamente e 10 foram eutanasiados. Treze ovinos, provenientes dos Surtos 1 e 4, apresentaram morte súbita e grande quantidade de espuma branca na cavidade nasal e oral e 30 ovinos, provenientes dos Surtos 2 e 3, apresentaram doença crônica com perda de peso, relutância em se movimentar, andar rígido, abdômen retraído e cifose. Doze ovinos foram necropsiados. Lesões de necropsia incluíam má condição da carcaça, com depleção dos depósitos de gordura, e mineralização de vários tecidos. Havia evidente rigidez das grandes artérias, que apresentavam superfície intimal irregular e dura, com múltiplas placas irregulares brancas e opacas. Áreas semelhantes de mineralização também eram observadas no endocárdio valvar ou mural, nas serosas uterina, omasal, ruminal e reticular e no parênquima renal. Em seis ovinos havia moderado a acentuado edema pulmonar e em sete ovinos havia áreas multifocais ou coalescentes, brancas e duras, na superfície subpleural dos pulmões. Histologicamente havia mineralização sistêmica dos tecidos, caracterizada por fina granulação basofílica em vários órgãos. Nas artérias, a mineralização era observada principalmente na túnica média e freqüentemente havia proliferação intimal e ocasional metaplasia condróide ou óssea da média. Em sete ovinos foi observada mineralização dos vasos da rete mirabile carotídea. No miocárdio e no pulmão, podiam ser observados focos de calcificação e metaplasia óssea em cardiomiócitos e septos alveolares, respectivamente. Em cada uma das propriedades onde ocorreram os casos havia infestação da pastagem por Nierembergia veitchii.
Palavras-chave: plantas tóxicas, doenças de ovinos, calcinose enzoótica, mineralização sistêmica, Nierembergia veitchii, patologia.

\section{ABSTRACT}

Sudden death and chronic disease were observed in sheep from four herds in three cities from Rio Grande do Sul, Brazil, between June 2001 and May 2006. From a total population at risk of 460 sheep of various ages 43 were affected, 29 died spontaneously and 10 were euthanatized. Thirteen sheep from outbreaks 1 and 4 had sudden death with large amount of froth in oral and nasal cavities; thirty sheep from outbreaks 2 and 3 had a chronic course of loss of weight, reluctance to move, stiff gait, tucked abdomen and kyphosis. A total of 12 sheep were necropsied. Gross changes included poor body condition with depletion of fat deposits and mineralization of several tissues. The large arteries were rigid and had a hard and irregular intimal surface due to irregular prominent whitish opaque plaques. Mineralization was also observed in valvar and mural endocardium and in the uterine, omasal, ruminal and reticular serosa and in the renal parenchyma. Moderate to severe lung edema was observed in six sheep and multifocal to coalescing hard white areas were observed in the subpleural lung parenchyma of seven sheep. Histologically there was systemic tissue mineralization characterized by fine basophilic granules deposited in several tissues. In the arteries mineralization was mainly in the subintimal media and frequently there was intimal proliferation and occasional chondroid and osseous metaplasia of the media. Mineralization of the carotid rete mirabile was observed in seven cases. Foci of mineralization and osseous metaplasia were also observed in the myocardium and alveolar septa. In each of the farms where the outbreaks occurred Nierembergia veitchii was found in the pastures.

'Programa de Pós-graduação em Medicina Veterinária, área de concentração em Patologia Veterinária, Universidade Federal de Santa Maria (UFSM), 97105-900, Santa Maria, RS, Brasil.

"Laboratório de Patologia Veterinária, Departamento de Patologia, UFSM, Santa Maria, RS, Brasil. E-mail: claudioslbarros@uol.com.br.*Autor para correspondência. 
Key words: poisonous plants, sheep diseases, enzootic calcinosis, systemic mineralization, Nierembergia veitchii, pathology.

\section{INTRODUÇÃO}

Nierembergia veitchii é uma planta rasteira encontrada no Rio Grande do Sul, onde cresce misturada à vegetação nativa. A planta floresce no período entre outubro e fevereiro, mas seu ciclo pode sofrer variações de acordo com as condições climáticas (TOKARNIA et al., 2000; MÉNDEZ \& RIET-CORREA, 2001). No Brasil, a intoxicação por $N$. veitchii em ovinos é conhecida desde o final da década de 1960 como calcinose enzoótica (BARROS et al., 1970) e foi descrita posteriormente em várias regiões do Estado do Rio Grande do Sul (RIET-CORREA et al., 1987; BARROS et al., 1992). São afetados ovinos de todas as idades, com exceção de cordeiros lactentes, e não há predisposição por sexo ou raça. Os índices de morbidade variam amplamente e dependem da quantidade de planta disponível em cada piquete; a mortalidade varia de 1 a $25 \%$. Bovinos raramente são afetados, em razão de possuírem hábitos alimentares diferentes aos dos ovinos, que pastejam a vegetação mais rasteira (RIETCORREA et al., 1987). Os sinais clínicos desenvolvidos pelos ovinos afetados são de uma doença caquetizante, caracterizada por emagrecimento progressivo, andar rígido, abdômen retraído, respiração ofegante e decúbito. Achados de necropsia são caracterizados pelo endurecimento e pela perda da elasticidade de artérias, principalmente as de grande calibre, que apresentam placas brancas e elevadas na túnica íntima. Essas lesões também podem ser observadas nas valvas cardíacas, pulmões, rins e útero. Histologicamente, as áreas brancas observadas na necropsia correspondem a focos de mineralização, decorrentes da absorção do princípio tóxico da planta, que provoca degeneração e calcificação de fibras elásticas, hipercalcemia e hiperfosfatemia.

O objetivo deste trabalho é descrever a epidemiologia, os sinais clínicos e os achados de necropsia e histopatológicos em quatro surtos de intoxicação por $\boldsymbol{N}$. veitchii em ovinos ocorridos entre junho de 2001 e maio de 2006 em três municípios do Rio Grande do Sul, nos quais foram observados: 1) um quadro clínico distinto, caracterizado por morte súbita decorrente de insuficiência respiratória aguda secundária a edema pulmonar; e 2) mineralização dos vasos da rete mirabile carotídea, uma lesão ainda não descrita em casos de calcinose enzoótica.

\section{MATERIAL E MÉTODOS}

Dados epidemiológicos e clínicos foram obtidos junto aos proprietários e veterinários encarregados dos casos. Os surtos foram numerados de 1-4 e necropsias foram realizadas em 12 ovinos (Tabela 1). Fragmentos de vários órgãos foram coletados, fixados em formol a $10 \%$, processados rotineiramente e corados pela técnica de hematoxilinaeosina (HE). Os encéfalos foram coletados inteiros, juntamente com o monobloco composto pelo gânglio de Gasser, pela rete mirabile carotídea e pela hipófise (GRH), e processados da mesma forma (BARROS \& MARQUES, 2003). Adicionalmente, seções de GRH foram submetidas à coloração pela técnica de von Kossa para demonstração de cálcio.

\section{RESULTADOS}

Um resumo dos dados epidemiológicos dos quatro surtos descritos está na tabela 1 . O surto 1 ocorreu no município de Jóia, em junho de 2001. Os ovinos apresentavam intolerância ao exercício e morte súbita, com grande quantidade de espuma na cavidade oral. Fragmentos de encéfalo e vários outros órgãos de um ovino, fêmea, com dois anos de idade, foram enviados ao Laboratório de Patologia Veterinária para exame histopatológico após morte espontânea.

O surto 2 ocorreu no município de Nova Palma, de dezembro de 2004 a janeiro de 2005. Os ovinos afetados eram provenientes de dois lotes na propriedade. O Lote A era composto de 55 ovinos de aproximadamente um ano de idade; desses, três adoeceram e morreram. No Lote B havia 60 ovelhas adultas, das quais 16 adoeceram e três morreram. Os ovinos desenvolveram sinais clínicos de doença crônica e caquetizante, caracterizados por emagrecimento progressivo, andar rígido, abdômen retraído e cifose. Durante uma semana, foram acompanhadas clinicamente e necropsiadas nove ovelhas de 3-5 anos, provenientes do Lote B. Esses ovinos apresentavam má condição corporal, relutância em se movimentar, andar rígido e decúbito. Quando se movimentavam, ocorria exacerbação dos sinais clínicos, dispnéia, taquicardia e, em alguns ovinos, podia ser observada espuma branca nas narinas. Na maioria dos ovinos podia ser notado endurecimento da artéria femoral à palpação. Um desses ovinos morreu espontaneamente um dia após ter sido forçado à movimentação e era o que apresentava os sinais mais acentuados da doença (Figura 1A). Os demais ovinos foram submetidos à eutanásia. 
Tabela 1 - Dados epidemiológicos dos surtos de intoxicação por Nierembergia veitchii em ovinos em quatro propriedades rurais do Rio Grande do Sul.

\begin{tabular}{|c|c|c|c|c|c|c|c|}
\hline Surto & Município & Éроса & $\begin{array}{l}\text { Ovinos no } \\
\text { rebanho }\end{array}$ & $\begin{array}{l}\text { Ovinos } \\
\text { afetados }\end{array}$ & $\begin{array}{l}\text { Ovinos } \\
\text { mortos }\end{array}$ & $\begin{array}{c}\text { Ovinos } \\
\text { eutanasiados }\end{array}$ & $\begin{array}{c}\text { Ovinos } \\
\text { necropsiados }\end{array}$ \\
\hline 1 & Jóia & jun/2001 & 100 & 10 & 10 & 0 & 1 \\
\hline 2 & Nova Palma & dez/2004 a jan/ 2005 & 115 & 19 & 6 & 9 & 9 \\
\hline 3 & Júlio de Castilhos & $\mathrm{jan} / 2005$ & 65 & 11 & 10 & 1 & 1 \\
\hline 4 & Júlio de Castilhos & $\mathrm{mai} / 2006$ & 180 & 3 & 3 & 0 & 1 \\
\hline
\end{tabular}

O surto 3 ocorreu no município de Júlio de Castilhos, em janeiro de 2005. No intervalo de um mês, morreram 10 ovinos com sinais de emagrecimento progressivo e apatia. Um ovino, fêmea, com quatro anos de idade, foi submetido à eutanásia e necropsiado.

O surto 4 ocorreu no município de Júlio de Castilhos em maio de 2006. Três ovinos morreram subitamente e apresentavam grande quantidade de espuma na cavidade nasal e oral. Uma ovelha, com dois anos de idade, foi necropsiada após morte espontânea.

Em todas as propriedades os ovinos estavam em piquetes de campo nativo infestados por N. veitchii.

Os achados de necropsia foram consistentes em todos os ovinos necropsiados, os quais eram caracterizados por má condição da carcaça e depleção dos depósitos de gordura. Havia espessamento, enrugamento e perda da elasticidade das grandes artérias elásticas (aorta, renal, femoral e carótida); em um ovino, essa alteração foi observada somente na artéria aorta. A íntima desses vasos apresentava superfície irregular e dura, com múltiplas placas irregulares brancas e opacas elevadas na túnica íntima (Figura 1B e 1C). Áreas semelhantes eram observadas como estrias ou placas de aproximadamente 2-5mm distribuídas no endocárdio da valva atrioventricular esquerda, ou endocárdio mural, e nas serosas uterina, omasal, ruminal e reticular. Em um ovino, foram observadas estrias brancas e firmes na região medular dos rins. Os pulmões estavam armados, brilhantes, úmidos e vermelhos em seis ovinos e havia moderada ou acentuada quantidade de espuma branca no interior da traquéia e brônquios; ao corte, grande quantidade de líquido fluía do parênquima pulmonar. Um ovino (proveniente do surto 4) apresentava grande quantidade de espuma branca na cavidade nasal e oral. Em sete ovinos havia áreas multifocais ou coalescentes, brancas e duras, na superfície pleural de ambos os pulmões, principalmente nas bordas.

Histologicamente, todos os ovinos apresentaram mineralização dos tecidos moles, que variou quanto à localização e intensidade nos 12 casos examinados. As lesões eram observadas principalmente nas grandes artérias elásticas e eram caracterizadas por áreas multifocais ou focalmente extensas de fina granulação basofílica na túnica média (Figura 1D). Em algumas áreas, havia metaplasia condróide ou óssea e a proliferação da íntima desses vasos foi um achado freqüente. Essas alterações também foram observadas em artérias cardíacas (Figura 1D), pulmonares e renais. No miocárdio e no pulmão, podiam ser observados focos de calcificação e metaplasia óssea em cardiomiócitos e septos alveolares, respectivamente, com infiltrado linfoistiocitário leve e células gigantes multinucleadas. A maioria dos alvéolos estava preenchida por material homogêneo eosinofílico (edema) nos ovinos dos surtos 1 e 4 . No rim, havia mineralização do epitélio tubular, principalmente na região medular. Em sete ovinos, foi observada mineralização dos vasos da rete mirabile carotídea (Figura 1E), evidenciada pela técnica de von Kossa (Figura 1F). Não foram observadas lesões nos encéfalos dos ovinos necropsiados.

\section{DISCUSSÃO}

O diagnóstico de intoxicação por $\boldsymbol{N}$. veitchii neste relato foi realizado com base nos achados epidemiológicos, clínicos, de necropsia e histopatológicos e confirmado pela constatação da presença da planta nas propriedades. Esses achados foram idênticos aos já relatados por outros autores em casos de calcinose enzoótica em ovinos (BARROS et al., 1970; RIET-CORREA et al., 1987; BARROS et al., 1992) e são semelhantes aos descritos na intoxicação por Solanum malacoxylon em bovinos no Rio Grande do Sul (RIET-CORREA et al., 1987). A diferenciação entre as duas condições é realizada com base na espécie afetada e na ocorrência das duas plantas. Intoxicação por $\boldsymbol{N}$. veitchii afeta principalmente ovinos em razão do hábito de pastejo rasteiro dessa espécie; além disso, surtos de intoxicação por $\boldsymbol{S}$. malacoxylon são raros no Rio Grande do Sul, pois a planta tem maior distribuição na Região Centro-Oeste do país (TOKARNIA et al., 


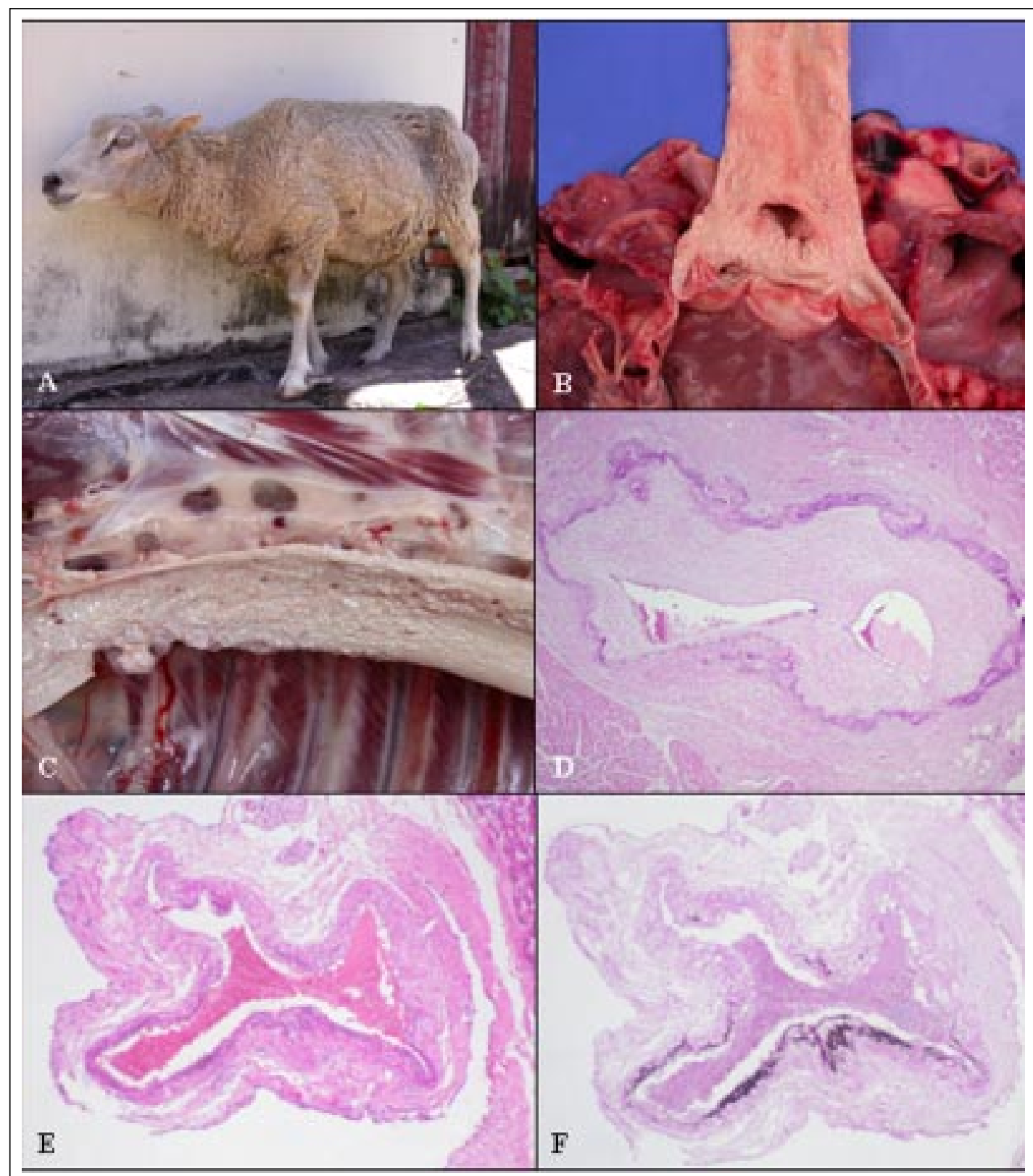

Figura 1 - Intoxicação por Nierembergia veitchii em ovinos. A. Ovino em má condição corporal e relutante em se movimentar. B. Artéria aorta, valvas semilunares. Superfície irregular e dura, com múltiplas placas brancas e opacas elevadas na túnica íntima. C. Artéria aorta torácica. Lesão semelhante à obseravada em B, mais acentuada. D. Artéria no coração com áreas lineares de granulação basofílica na túnica média (mineralização) e acentuada proliferação da túnica íntima. Hematoxilina-eosina. E. Vaso da rete mirabile carotídea. As áreas de mineralização (basofílicas) observadas na hematoxilina-eosina são mais bem evidenciadas (em negro) pela técnica de Von Kossa (F).

2000); adicionalmente, casos de calcinose sem causa definida em bovinos e ovinos têm sido descritos nessas regiões (NAKAZATO et al., 2005; SANTOS et al., 2005).

Em dois surtos deste estudo os casos foram observados nos meses de dezembro de 2004 (surto 2) e janeiro de 2005 (surto 3), época em que costuma ocorrer um maior número de casos da doença. Surtos de intoxicação por $\boldsymbol{N}$. veitchii são sazonais e iniciam a partir de setembro-outubro, durante a floração da planta, e se estendem até meados de janeiro-fevereiro, quando a infestação diminui nos pastos (RIETCORREA et al., 1987). Nos surtos 1 e 4 deste estudo, os

Ciência Rural, v.37, n.5, set-out, 2007. 
casos foram registrados em junho de 2001 e maio de 2006, respectivamente, e os ovinos provenientes dessas duas propriedades apresentaram uma manifestação clínica diferente do que é descrito em casos de intoxicação por $\boldsymbol{N}$. veitchii. Nesses casos, acentuado edema pulmonar resultou na morte dos ovinos por insuficiência respiratória aguda. Circunstâncias semelhantes foram observadas em casos da doença (BARROS et al., 1992) em ovelhas após a parição e foram atribuídas à calcificação das valvas cardíacas, que culminaram com edema pulmonar e morte dos animais. Adicionalmente, esse tipo de manifestação clínica pode ser atribuído ao fato de que, no final do outono e início do inverno (época de parição de ovinos no RS), as reservas energéticas dos ovinos estejam escassas, o que favoreceria uma exacerbação do quadro clínico e a morte dos animais afetados.

O princípio tóxico de $N$. veitchii é um derivado glicosídeo do calcitriol, ou $1,25(\mathrm{OH})_{2} \mathrm{D}_{3}$, e seu efeito direto sobre as fibras elásticas teciduais e a indução de hipercalcemia são os dois fatores responsáveis pela mineralização dos tecidos nos ovinos que ingerem a planta. O espessamento da íntima das artérias provavelmente seja o resultado da ação dessa substância sobre as células musculares lisas da média, induzindo sua diferenciação, migração para a íntima e proliferação no espaço intimal, como foi evidenciado pela reação positiva pela técnica de imunoistoquímica à $\alpha$-actina de células musculares lisas (VASCONCELOS et al., 1998).

Em sete casos deste estudo foi observada mineralização dos vasos da rete mirabile carotídea. Essa lesão ainda não havia sido descrita em casos de calcinose enzoótica, provavelmente devido ao fato de que o monobloco GRH não é normalmente examinado na rotina de necropsia de ruminantes nos laboratórios de diagnóstico. A partir de uma série de estudos de doenças do sistema nervoso central (SNC) de ruminantes, foi introduzida em nossa rotina de necropsia a coleta, juntamente com o SNC, do monobloco composto pelo GRH. Esse procedimento demonstrou que essa estrutura tem utilidade no diagnóstico diferencial de algumas doenças do SNC de bovinos (RECH et al., 2006) e os resultados deste trabalho demonstram sua importância também na espécie ovina. Depressão ou apatia, andar rígido e decúbito são sinais clínicos freqüentemente desenvolvidos por ovinos afetados pela calcinose enzoótica e podem ser confundidos com sinais de doenças neurológicas (INNES \& SAUNDERS, 1962). Nesses casos, o exame do GRH associado aos dados epidemiológicos seria definitivo no diagnóstico de intoxicação por $N$. veitchii em aproximadamente $70 \%$ dos casos (se for considerado que em apenas 10 casos essa estrutura pôde ser examinada), principalmente em ocasiões onde não é possível o exame do encéfalo (RECH et al., 2006) ou quando o veterinário encarregado, suspeitando de doença neurológica, remete somente a cabeça do animal para o exame, como é comum em nossa rotina.

De uma população total sob risco de 460 ovinos de várias idades em quatro propriedades rurais, 43 foram afetados pela doença e 29 morreram espontaneamente, o que resulta em um coeficiente de morbidade de 9,34\%. Como 10 ovinos foram eutanasiados e não se sabe se houve recuperação de outros animais nos rebanhos, não foi possível calcular os índices de mortalidade e letalidade.

Não há tratamento específico para a intoxicação por $\boldsymbol{N}$. veitchii e a remoção dos ovinos afetados do piquete infestado pela planta pode propiciar uma melhora clínica dos animais afetados, porém não é muito eficaz (SCHILD, 1993; TOKARNIA et al., 2000; MÉNDEZ \& RIET-CORREA, 2001). O veterinário responsável pelos casos do surto 1 informou que os outros ovinos foram retirados da pastagem logo após o diagnóstico ter sido feito e que não havia observado novos casos. Podem ser realizadas medidas de controle da planta ou o uso de bovinos na época de sua ocorrência, pois essa espécie normalmente não ingere a planta devido aos seus hábitos alimentares e, caso haja consumo, são necessárias grandes quantidades da planta para o desenvolvimento da doença (SCHILD, 1993; TOKARNIA et al., 2000; MÉNDEZ \& RIET-CORREA, 2001). Outra opção é que ovinos com estado corporal razoável poderiam ser destinados ao abate com o objetivo de reduzir em parte as perdas econômicas (BARROS et al., 1992).

A partir dos casos deste estudo, é possível concluir que casos de morte súbita em ovinos causados pela intoxicação por $\boldsymbol{N}$. veitchii podem ocorrer ocasionalmente, principalmente em ovelhas no período pré-parto. Além disso, na maioria desses casos, há mineralização dos vasos da rete mirabile carotídea, o que demonstra a importância do exame dessa estrutura.

\section{AGRADECIMENTOS EAPRESENTAÇÃO}

Ao Conselho Nacional de Desenvolvimento Científico e Tecnológico (CNPq), pela concessão de bolsa ao primeiro autor.

Parte da Tese de Doutorado em Medicina Veterinária do primeiro autor.

\section{REFERÊNCIAS}

BARROS, C.S.L; MARQUES, G.H.F. Procedimentos para o diagnóstico das doenças do sistema nervoso central de 
bovinos. Brasília: Departamento de Defesa Animal, Ministério da Agricultura, Pecuária e Abastecimento (MAPA), 2003. 50p.

BARROS, S.S. et al. Evolução clínica e reversibilidade das lesões da calcinose enzoótica dos ovinos induzida por Nierembergia veitchii. Pesquisa Veterinária Brasileira, v.12, n.1/2, p.510, 1992.

BARROS, S.S. et al. Zur kalzinose beim schaf. Deutsche Tierärtzliche Wochenschrift, v.77, p.321-356, 1970.

INNES, J.R.M.; SAUNDERS, L.Z. Comparative neuropathology. New York: Academic, 1962. 837p.

MÉNDEZ, M.C.; RIET-CORREA, F. Intoxicações por plantas e micotoxinas. In: RIET-CORREA, F. et al. Doenças de ruminantes e eqüinos. São Paulo: Varela, 2001. Cap.3, p.219-299.

NAKAZATO, L. et al. Enzootic calcinosis in the pantanal of Mato Grosso State. Arquivo Brasileiro de Medicina Veterinária e Zootecnia, v.57, supl.1, p.21, 2005.

RECH, R.R. et al. Histomorfologia do gânglio de Gasser, da rete mirabile carotídea e da hipófise de bovinos: estudo de 199 casos. Pesquisa Veterinária Brasileira, v.26, n.2, p.105111,2006

RIET-CORREA, F. et al. Enzootic calcinosis in sheep caused by the ingestion of Nierembergia veitchii (Solanaceae). Pesquisa Veterinária Brasileira, v.7, n.3, p.85-95, 1987.

SANTOS, A.S. et al. Calcinose em ruminantes de etiologia desconhecida no Estados de Goiás - GO. Arquivo Brasileiro de Medicina Veterinária e Zootecnia, v.57, supl.1, p.76, 2005.

SCHILD, A.L. Intoxicação por Nierembergia veitchii. In: RIET-CORREA, F. et al. Intoxicações por plantas e micotoxicoses em animais domésticos. Pelotas: Hemisfério Sul, 1993. Cap.13, p.270-278.

TOKARNIA, C.H. et al. Plantas tóxicas do Brasil. Rio de Janeiro: Helianthus, 2000. 310p.

VASCONCELOS, R.O. et al. Arterial diffuse intimal thickening associated with enzootic calcinosis of sheep. Pesquisa Veterinária Brasileira, v.18, n.1, p.9-15, 1998. 